\title{
High-speed $\mathrm{C}-\mathrm{H}$ chlorination of ethylene carbonate using a new photoflow setup
}

\author{
Takayoshi Kasakado ${ }^{\ddagger 1}$, Takahide Fukuyama ${ }^{\star 2}$, Tomohiro Nakagawa ${ }^{\ddagger}$, Shinji Taguchi ${ }^{3}$ \\ and Ilhyong Ryu ${ }^{*} 1,4$
}

\section{Letter}

\section{Address:}

${ }^{1}$ Organization for Research Promotion, Osaka Prefecture University, Sakai, Osaka 599-8531, Japan, ${ }^{2}$ Department of Chemistry, Graduate School of Science, Osaka Prefecture University, Sakai, Osaka 599-8531, Japan, ${ }^{3}$ Wakayama Research \& Development Group, Nankai Chemical Co. Ltd., 1-1-38 Kozaika, Wakayama 641-0007, Japan and ${ }^{4}$ Department of Applied Chemistry, National Yang Ming Chiao Tung University (NYCU), Hsinchu 30010, Taiwan

\section{Email:}

Takahide Fukuyama* - fukuyama@c.s.osakafu-u.ac.jp; Ilhyong Ryu* ryu@c.s.osakafu-u.ac.jp

* Corresponding author $\ddagger$ Equal contributors

Keywords:

$\mathrm{C}-\mathrm{H}$ chlorination; chlorine gas; ethylene carbonate; photo flow reactor; vinylene carbonate
Beilstein J. Org. Chem. 2022, 18, 152-158.

https://doi.org/10.3762/bjoc.18.16

Received: 04 December 2021

Accepted: 21 January 2022

Published: 27 January 2022

This article is part of the thematic issue "Platform and enabling technologies in organic synthesis".

Guest Editor: P. Heretsch

(C) 2022 Kasakado et al.; licensee Beilstein-Institut. License and terms: see end of document.

\begin{abstract}
We report the high-speed $\mathrm{C}-\mathrm{H}$ chlorination of ethylene carbonate, which gives chloroethylene carbonate, a precursor to vinylene carbonate. A novel photoflow setup designed for a gas-liquid biphasic reaction turned out to be useful for the direct use of chlorine gas. The setup employed sloped channels so as to make the liquid phase thinner, ensuring a high surface-to-volume ratio. When ethylene carbonate was introduced to the reactor, the residence time was measured to be 15 or $30 \mathrm{~s}$, depending on the slope of the reactor set at 15 or $5^{\circ}$, respectively. Such short time of exposition sufficed the photo $\mathrm{C}-\mathrm{H}$ chlorination. The partial irradiation of the flow channels also sufficed for the $\mathrm{C}-\mathrm{H}$ chlorination, which is consistent with the requirement of photoirradiation for the purpose of radical initiation. Near-complete selectivity for single chlorination required the low conversion of ethylene carbonate such as $9 \%$, which was controlled by limited introduction of chlorine gas. At a higher conversion of ethylene carbonate such as $61 \%$, the selectivity for monochlorinated ethylene carbonate over dichlorinated ethylene carbonate was $86 \%$. We found that the substrate contamination with water negatively influenced the performance of the $\mathrm{C}-\mathrm{H}$ chlorination.
\end{abstract}

\section{Introduction}

The $\mathrm{C}-\mathrm{H}$ chlorination by molecular chlorine is a highly exothermic reaction that proceeds via a radical chain mechanism as illustrated in Scheme 1 [1-6]. Frequently, photoirradiation is used for radical initiation through homolysis of the $\mathrm{Cl}-\mathrm{Cl}$ bond to generate chlorine radicals. In a subsequent step, a $\mathrm{S}_{\mathrm{H}} 2$ reaction by chlorine radicals at $\mathrm{C}-\mathrm{H}$ bonds generates alkyl radicals 
and $\mathrm{HCl}$. The second $\mathrm{S}_{\mathrm{H}} 2$ reaction between alkyl radicals and molecular chlorine then occurs to give the $\mathrm{C}-\mathrm{H}$ chlorinated product and a chlorine radical, sustaining the radical chain. Chlorine gas is a cheap feedstock since it is formed as a byproduct of the electrolysis of $\mathrm{NaCl}$ to produce $\mathrm{NaOH}$ in an industrial process [7]. We felt that $\mathrm{C}-\mathrm{H}$ chlorination would be updated by using scalable flash chemistry [8].

$\mathrm{R}-\mathrm{H}+\mathrm{Cl}_{2} \longrightarrow \mathrm{Rv}-\mathrm{Cl}+\mathrm{HCl}$

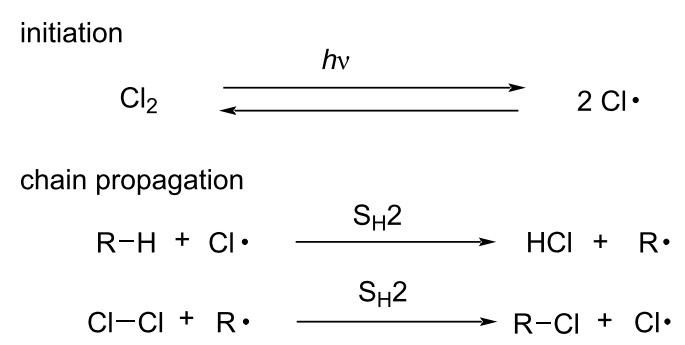

Scheme 1: Radical chain mechanism for a photo-induced C-H chlorination reaction.

Flow C-H chlorination using a compact flow reactor is highly desirable in terms of efficiency and safety in handling highly toxic gases such as chlorine. In 2002, Jähnisch and co-workers reported the first microflow chlorination of 2,4-diisocyano-1methylbenzene, which used a falling-film reactor developed by IMM [9]. While the flow rate employed was quite low $(0.12$ $\mathrm{mL} / \mathrm{min}$ of toluene), the residence time was less than 14 seconds. More recent studies on flow $\mathrm{C}-\mathrm{H}$ chlorination reactions focused on the use of $\mathrm{Cl}_{2}$ gas in situ generated by photolysis of sulfuryl chloride [10] or by acid treatment of $\mathrm{NaOCl}$ $[11,12]$. We thought that if rationally designed scalable photoflow setups were available, flow $\mathrm{C}-\mathrm{H}$ chlorination reactions using chlorine gas would be able to focus on production. In this study, we tested a novel photoflow setup consisting of quartz-made straight-line reactors, which are provided from MiChS (LX-1, Figure 1a) and a high-power LED (MiChS LED-s, $365 \pm 5 \mathrm{~nm}$, Figure 1b) [13]. Each channel track has a $2 \mathrm{~mm}$ depth and $557 \mathrm{~mm}$ length, while the width varies from 6 or $13 \mathrm{~mm}$ depending on the number of channels 7 or 5 , respectively. The flow photoreactor is embedded into an aluminum frame equipped with a heat carrier channel. The design concepts including angle settings to ensure a thin liquid layer are summarized in Figure 1.

We chose the $\mathrm{C}-\mathrm{H}$ chlorination of ethylene carbonate (1) as a model reaction (Scheme 2). Chlorinated ethylene carbonate $\mathbf{2}$ is a precursor to vinylene carbonate (3), which is used as an electrolyte additive for Li-ion batteries [14-20]. Vinylene carbonate also serves as a useful synthetic building block for Diels-Alder reactions [21-25] and polymerization [26-30].

\section{Results and Discussion}

Using a PTFE tube and PTFE connectors, we connected the photoflow setup with a chlorine gas cylinder through a floating gas level meter in a fume hood (Figure 2). Since ethylene carbonate (1) melts between $34-37{ }^{\circ} \mathrm{C}$, we preheated the container of 1 using an oil bath at $70{ }^{\circ} \mathrm{C}$ and pumped it to the photoreactor. In the reactor, hot water $\left(80^{\circ} \mathrm{C}\right)$ was circulated through a hole channel manufactured in an aluminum-made frame to keep the contacted glass reactor warm. The LED lamp was placed on the upper side of the reactor with a $20^{\circ}$ angle to the reactor surface. The exiting gases $\left(\mathrm{HCl}\right.$ and unreacted $\left.\mathrm{Cl}_{2}\right)$ were trapped by an aqueous $\mathrm{NaOH}$ solution $(1.7 \mathrm{M})$.

The reactors are set with a slope of 15 or $5^{\circ}$ to achieve a thin substrate layer causing a rapid gas/liquid biphasic reaction. The residence time was estimated to be 15 and 30 seconds, respectively (for the measurement, ethylene carbonate was introduced in the absence of chlorine gas). After the experiments, chlorine gas that remained inside the flow setup was flushed with $\mathrm{N}_{2}$ gas. In general, we used ethylene carbonate (1) with the grade containing less than $0.03 \%$ of water. The results are summarized in Table 1.

When the reaction of ethylene carbonate (1, flow rate: $74.9 \mathrm{mmol} / \mathrm{min}$, containing $0.03 \%$ of $\mathrm{H}_{2} \mathrm{O}$ ) with 0.17 equiv of $\mathrm{Cl}_{2}$ gas (flow rate: $12.5 \mathrm{mmol} / \mathrm{min}$ ) was carried out under irradiation by UV-LED $(240 \mathrm{~W})$ with a $15^{\circ}$ reactor angle, the desired chloroethylene carbonate (2) was formed selectively with a $9 \%$ conversion of 1 (Table 1 , entry 1 ). When 0.23 equiv of $\mathrm{Cl}_{2}$ was used, the selectivity became $96 \%$ with $12 \%$ conversion of $\mathbf{1}$, in which a small amount of undesired 1,2-dichloroethylene carbonate (2') was detected by GC (Table 1, entry 2). When 0.45 equiv of $\mathrm{Cl}_{2}$ was used, the conversion of 1 increased to $21 \%$ and the selectivity of 2 became $91 \%$ (Table 1 , entry 3 ). The reaction of $\mathbf{1}$ with one equivalent of $\mathrm{Cl}_{2}$ gave $\mathbf{2}$ and $\mathbf{2}$ ' in a ratio of 89:11 with $39 \%$ conversion of $\mathbf{1}$ (Table 1, entry 4). When the reaction mixture was circulated twice, we observed a higher conversion of $\mathbf{1}(87 \%)$ and obtained a 74:26 mixture of 2 and 2' (Table 1, entry 5). Then, we limited the feeding of $\mathbf{1}$ (flow rate: $46.4 \mathrm{mmol} / \mathrm{min}$ ) in order to increase conversion, which worked well. The reaction of 1 with 1.97 equiv of $\mathrm{Cl}_{2}$ resulted in 61\% conversion of $\mathbf{1}$ and an 86:14 ratio of $\mathbf{2}$ and $\mathbf{2}$, (Table 1, entry 6). When a lower feeding of $1(29.6 \mathrm{mmol} / \mathrm{min})$ and an excess amount of $\mathrm{Cl}_{2}$ (3.09 equiv) were used, higher conversion of $1(76 \%)$ was attained with the selectivity of $84: 16$ (Table 1, entry 7). The irradiation at $600 \mathrm{~W}$ gave an almost similar result (Table 1, entries 8 and 9), which suggested that $240 \mathrm{~W}$ sufficed the reaction. Indeed, when the reaction was 
(a) Photoflow Reactor, MiChS LX-1
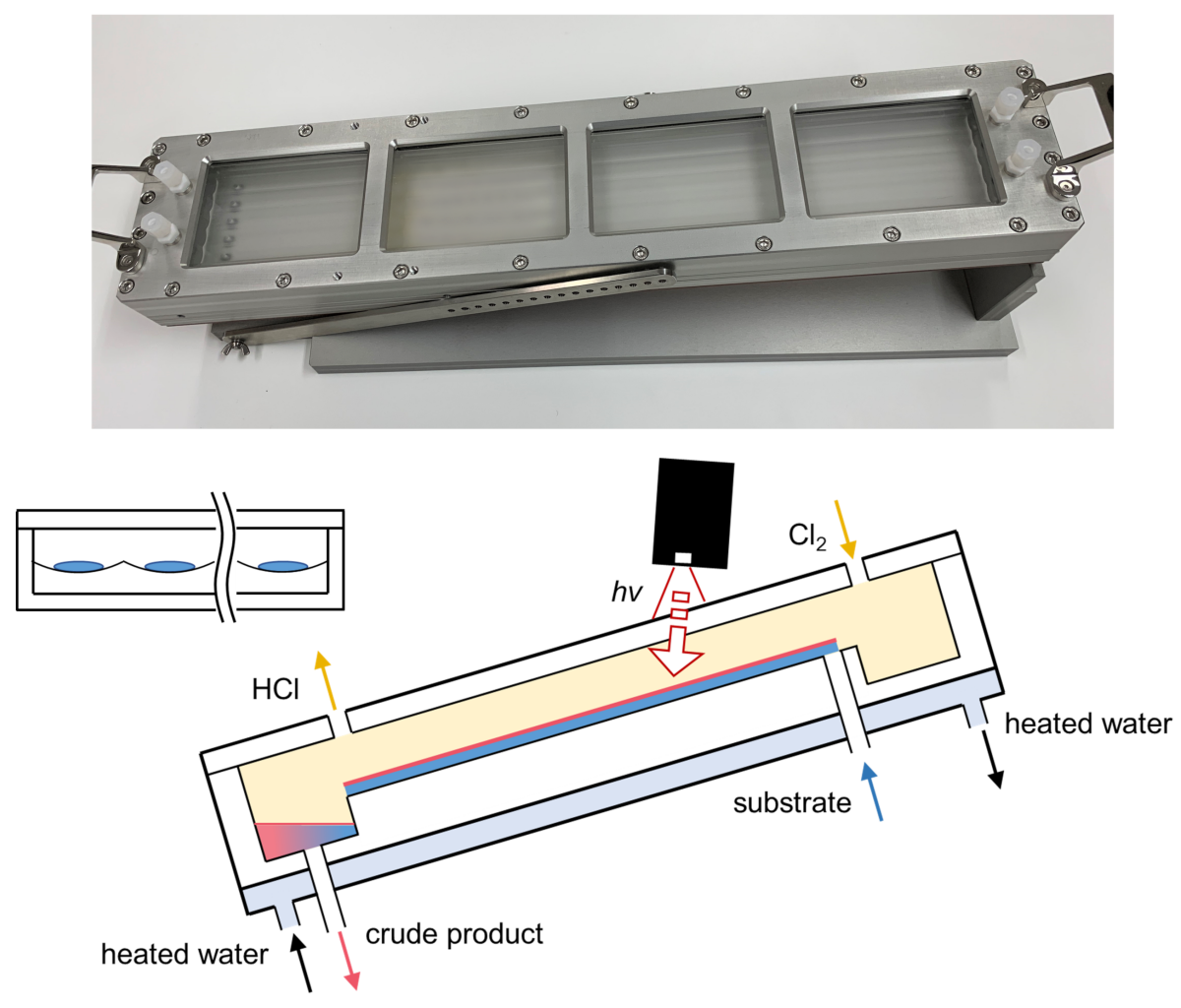

Concepts • quartz-glass made

- slope setting for thin liquid phase

- minimum use of chlorine gas

- gas outlet for hydrogen chloride

- partial photoirradiation

- heat control function in the aluminum frame

(b) MiChS LED-s
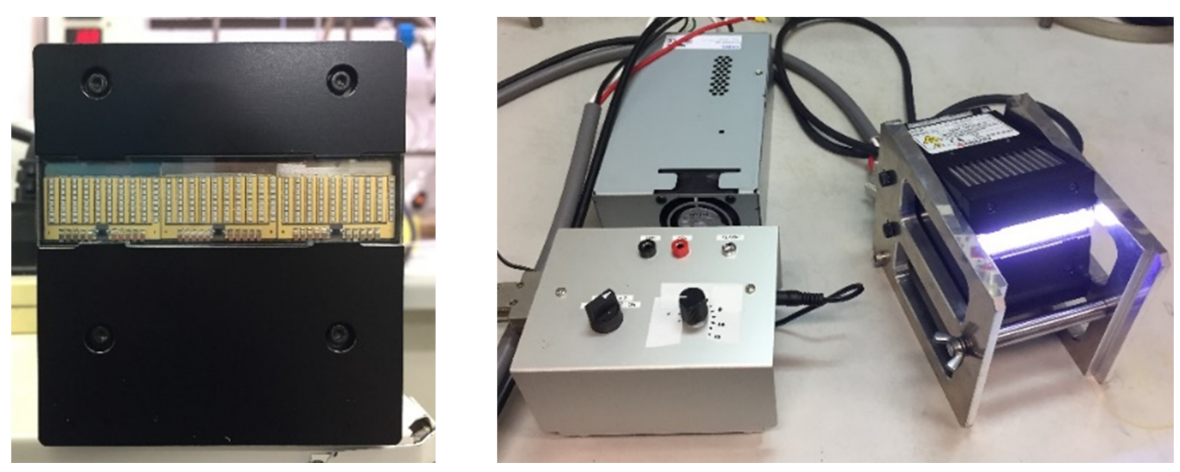

Figure 1: Components for photoflow setup: (a) MiChS LX-1 reactor and (b) MiChS LED-s (365 $\pm 5 \mathrm{~nm}, 60-600 \mathrm{~W}$ ).

carried out with a shallow reactor angle such as $5^{\circ}$, the conversion of 1 increased from 49 to $61 \%$ (Table 1 , entries 8 and 10). This is due to the extended residence time from 15 to $30 \mathrm{~s}$. Flow gas/liquid reactions are often carried out using a tubular reactor and mixer under slug flow conditions. However, it is not easy to apply such conditions to the present photochlorination reaction since the volume of the $\mathrm{Cl}_{2}$ gas is ca. 400 times larger than that of ethylene carbonate (for entry 8 in Table 1). In addition, a much longer tubular reactor would be required to ensure 15-30 s residence time. 


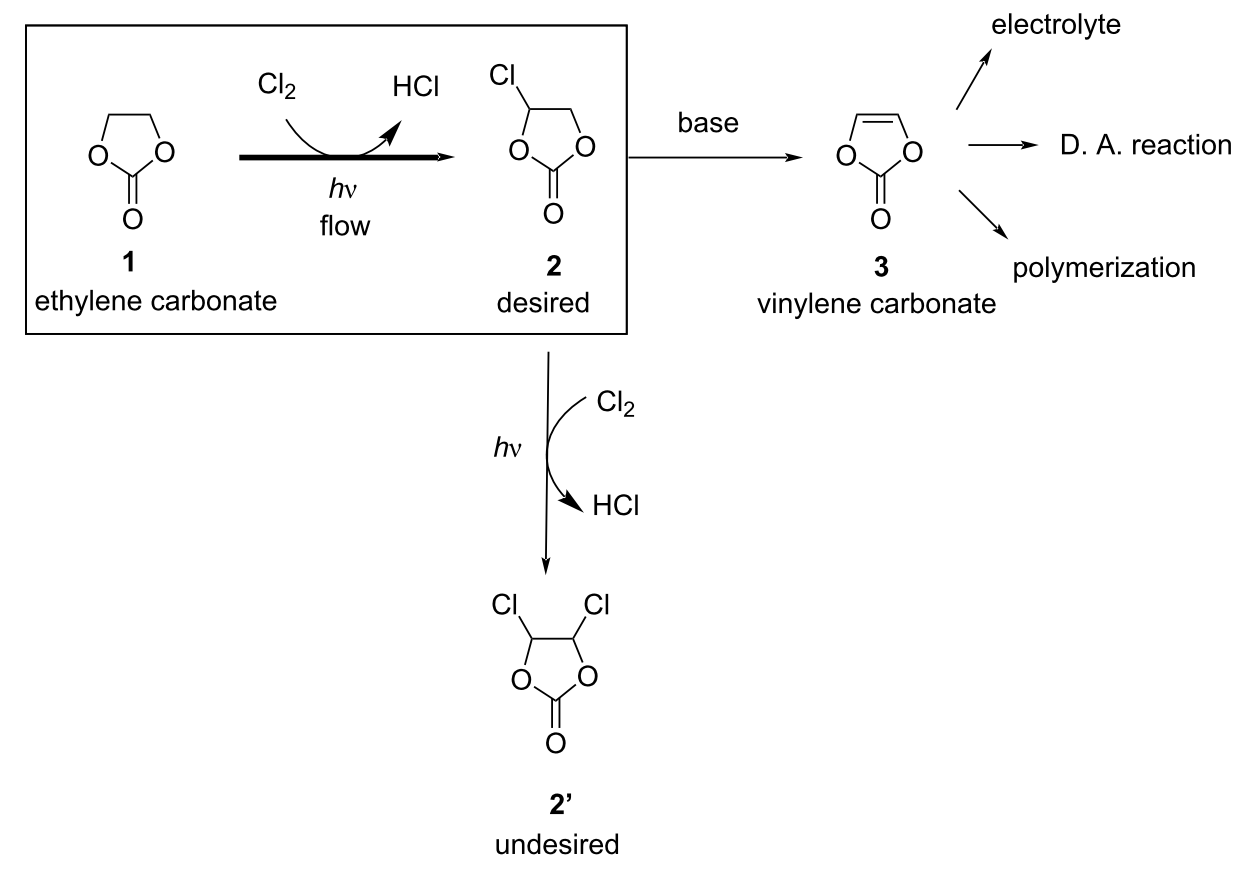

Scheme 2: Model reaction: photoflow C-H chlorination of ethylene carbonate (1) to chloroethylene carbonate (2).

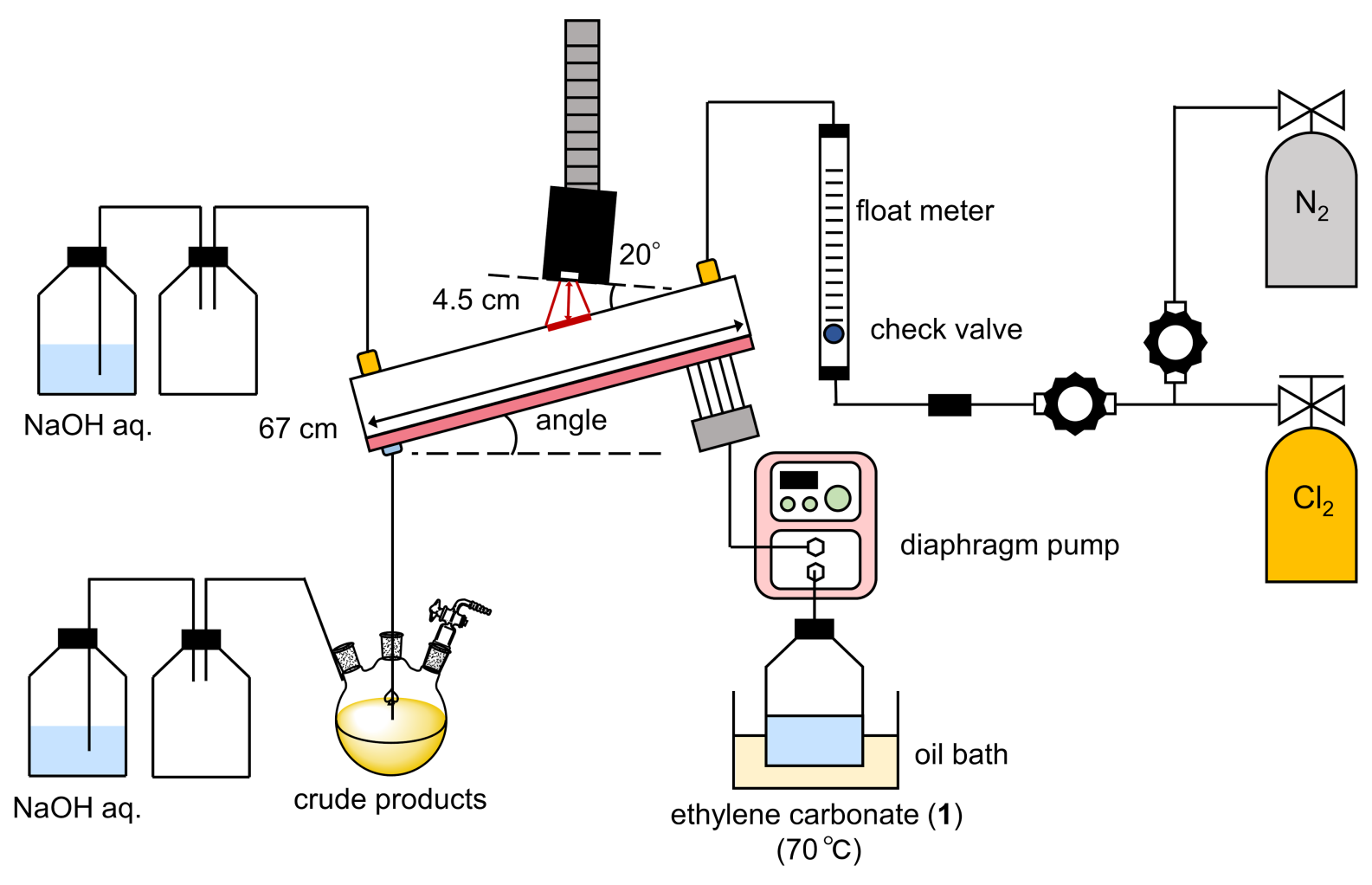

Figure 2: Photoflow setup for the $\mathrm{C}-\mathrm{H}$ chlorination of ethylene carbonate (1). 


\begin{tabular}{|c|c|c|c|c|c|c|c|}
\hline \multirow[t]{2}{*}{ entry } & \multirow[t]{2}{*}{ angle $\left(^{\circ}\right)$} & \multicolumn{2}{|c|}{ flow rate } & \multirow[t]{2}{*}{ UV-LED (W) } & \multirow[t]{2}{*}{ conversion $(\%)^{b}$} & \multicolumn{2}{|c|}{ selectivity $(\%)^{b}$} \\
\hline & & $1^{\mathrm{a}}(\mathrm{mmol} / \mathrm{min})$ & $\mathrm{Cl}_{2}(\mathrm{mmol} / \mathrm{min})$ (equiv) & & & 2 & 2' \\
\hline 1 & 15 & 74.9 & $12.5(0.17)$ & 240 & 9 & 100 & 0 \\
\hline 2 & 15 & 74.9 & $17.4(0.23)$ & 240 & 12 & 96 & 4 \\
\hline 3 & 15 & 74.9 & $33.9(0.45)$ & 240 & 21 & 91 & 9 \\
\hline 4 & 15 & 74.9 & $75.9(1.01)$ & 240 & 39 & 89 & 11 \\
\hline $5^{c}$ & 15 & 74.9 & $75.9+75.9(2.02)$ & 240 & 87 & 74 & 26 \\
\hline 6 & 15 & 46.4 & $91.5(1.97)$ & 240 & 61 & 86 & 14 \\
\hline 7 & 15 & 29.6 & $91.5(3.09)$ & 240 & 76 & 84 & 16 \\
\hline 8 & 15 & 117.6 & $146.5(1.25)$ & 240 & 49 & 78 & 22 \\
\hline 9 & 15 & 117.6 & $143.7(1.22)$ & 600 & 47 & 78 & 22 \\
\hline 10 & 5 & 117.6 & $146.5(1.25)$ & 240 & 61 & 79 & 21 \\
\hline
\end{tabular}

${ }^{a}$ Reactions were conducted by using LX-1 with a reactor angle of $15^{\circ}$ or $5^{\circ}$ (entry 10). Photoirradiation was carried out by using LEDs $(365 \pm 5 \mathrm{~nm}$ at the power of 240 or $600 \mathrm{~W}$ ). Ethylene carbonate (1) contains $0.03 \%$ of $\mathrm{H}_{2} \mathrm{O}$. b Determined by GC analysis. ${ }^{\mathrm{C}}$ Reaction mixture was circulated twice.

We then investigated the effect of contamination with water on the reaction, since $\mathrm{Cl}_{2}$ gas is known to react with $\mathrm{H}_{2} \mathrm{O}$ under irradiation conditions [31] and the results are summarized in Table 2. The flow rate of $\mathbf{1}$ and the equivalents of chlorine to $\mathbf{1}$ were set to be $187 \mathrm{mmol} / \mathrm{min}$ and $0.60-0.69$, respectively. The reactor angle and light power were $15^{\circ}$ and $240 \mathrm{~W}$, respectively. The chlorination reaction using an ordinary grade of the substrate 1 containing $0.03 \%$ of water gave a $96: 4$ ratio of products $\mathbf{2}$ and $\mathbf{2}$, with $26 \%$ conversion of $\mathbf{1}$ (Table 2, entry 1). In contrast, when we used substrate 1 containing $0.15 \%$ of water, the conversion decreased to $11 \%$ (Table 2, entry 2). With $0.76 \%$ of water, the conversion decreased further to $9 \%$ (Table 2, entry 3 ). These results suggest that the reaction has to be carried out carefully under dry conditions.

\section{Conclusion}

In this work, we reported that a novel photoflow setup designed for a gas-liquid biphasic reaction turned out to be useful for the $\mathrm{C}-\mathrm{H}$ chlorination using chlorine gas in flow. Two decades after the first report on the microflow chlorination of a toluene derivative by Jähnisch and co-workers, we propose a new photoflow setup for $\mathrm{C}-\mathrm{H}$ chlorination using chlorine gas, applicable to scalable flow $\mathrm{C}-\mathrm{H}$ chlorination. In our test reaction using $\mathrm{C}-\mathrm{H}$ chlorination of ethylene carbonate (1), chloroethylene carbonate (2) was obtained in good to excellent selectivity by tuning the flow rates of $\mathbf{1}$ and chlorine gas. Partial irradiation of the flow channel is sufficient for the $\mathrm{C}-\mathrm{H}$ chlorination, consistent with the requirement for light irradiation for the radical initiation step. If we apply the conditions to give $80 \%$ selectivity with $60 \%$ conversion with $30 \mathrm{~s}$ residence time, around 15 kilograms of chloroethylene carbonate (2) can be synthesized per day, which suggests the high potential of the present photoflow setup. We also demonstrated that the contamination with water had a negative impact on the reaction and the system should be kept dry for continuous production. We are now investigating some other photo gas-liquid flow reactions, which will be reported in due course.

\section{Experimental}

The photoflow setup consisting of a flow photoreactor LX-1 and UV-LEDs were supplied from MiChS Inc., Ltd. (http://www.michs.jp). The angle of the photoflow reactor was set to be 15 or $5^{\circ}$ and heated water at $80^{\circ} \mathrm{C}$ was circulated in a channel of an aluminum-made frame to avoid solidification of

\begin{tabular}{|c|c|c|c|c|c|c|}
\hline \multirow[t]{2}{*}{ entry } & \multirow{2}{*}{$\begin{array}{c}\text { water } \\
\text { contamination }\end{array}$} & \multicolumn{2}{|c|}{ flow rate } & \multirow[t]{2}{*}{ conversion $(\%)^{\mathrm{b}}$} & \multicolumn{2}{|c|}{ selectivity $(\%)^{\mathrm{b}}$} \\
\hline & & $1^{\mathrm{a}}(\mathrm{mmol} / \mathrm{min})$ & $\mathrm{Cl}_{2}(\mathrm{mmol} / \mathrm{min})$ (equiv) & & 2 & 2' \\
\hline 1 & $0.03 \%$ & 187.0 & $126.8(0.68)$ & 26 & 96 & 4 \\
\hline 2 & $0.15 \%$ & 187.0 & $112.7(0.60)$ & 11 & 92 & 8 \\
\hline 3 & $0.76 \%$ & 187.0 & $118.3(0.63)$ & 9 & 100 & 0 \\
\hline
\end{tabular}

${ }^{a}$ Reactions were conducted by using LX-1 with a rector angle of $15^{\circ}$ and LEDs ( $\left.240 \mathrm{~W}\right) .{ }^{\mathrm{b}}$ Measured by GC. 
ethylene carbonate (1), whose melting point is $34-37^{\circ} \mathrm{C}$. The UV-LED $(365 \pm 5 \mathrm{~nm})$ was set with an angle of $20^{\circ}$ to the reactor surface. Ethylene carbonate (1) preheated to $70{ }^{\circ} \mathrm{C}$ was fed into each channel of the flow photoreactor by using a diaphragm pump. At the same time, chlorine gas was fed into the reactor from the top-side inlet. Evolved $\mathrm{HCl}$ gas and unreacted $\mathrm{Cl}_{2}$ gas were trapped by an aqueous $1.7 \mathrm{M} \mathrm{NaOH}$ solution. The first eluted solution was discarded for $3 \mathrm{~min}$ after which the eluted solution was collected for analysis. GC analysis was performed on a Shimadzu GC-2014 equipped with an FID detector using an Agilent J\&W DB-1 column $(\varnothing 0.25 \mathrm{~mm} \times 30 \mathrm{~m}$ ) under the following conditions: initial oven temperature: $40{ }^{\circ} \mathrm{C}$, temperature change rate of $5{ }^{\circ} \mathrm{C} / \mathrm{min}$ to $250{ }^{\circ} \mathrm{C}$, hold at this temperature for $10 \mathrm{~min}$. Yields were determined by using the percentage peak area method with compensation for the relative sensitivities of each component Product 2 and byproduct 2 , were confirmed by ${ }^{1} \mathrm{H}$ and ${ }^{13} \mathrm{C}$ NMR analysis (see Supporting Information File 1)

\section{Supporting Information}

\section{Supporting Information File 1}

GC analysis and NMR spectra of the crude reaction mixture for the chlorination of compound $\mathbf{1}$.

[https://www.beilstein-journals.org/bjoc/content/ supplementary/1860-5397-18-16-S1.pdf]

\section{Acknowledgements}

We thank Prof. Masaaki Sato and Dr. Hitoshi Mitsui at MiChS Inc. for useful discussions. IR thanks the Center for Emergent Functional Matter Science at NYCU for support.

\section{ORCID ${ }^{\circledR}$ iDs}

Takahide Fukuyama - https://orcid.org/0000-0002-3098-2987 Ilhyong Ryu - https://orcid.org/0000-0001-7715-4727

\section{Preprint}

A non-peer-reviewed version of this article has been previously published as a preprint: https://doi.org/10.3762/bxiv.2021.84.v1

\section{References}

1. Ingold, K. U.; Lusztyk, J.; Raner, K. D. Acc. Chem. Res. 1990, 23, 219-225. doi:10.1021/ar00175a003

2. Fletcher, B.; Suleman, N. K.; Tanko, J. M. J. Am. Chem. Soc. 1998, 120, 11839-11844. doi:10.1021/ja982289e

3. Sun, N.; Klabunde, K. J. J. Am. Chem. Soc. 1999, 121, 5587-5588. doi:10.1021/ja990084f

4. Pease, R. N.; Walz, G. F. J. Am. Chem. Soc. 1931, 53, 3728-3737. doi:10.1021/ja01361a016
5. Brown, H. C.; Kharasch, M. S.; Chao, T. H. J. Am. Chem. Soc. 1940, 62, 3435-3439. doi:10.1021/ja01869a040

6. Kharasch, M. S.; Berkman, M. G. J. Org. Chem. 1941, 6, 810-817. doi:10.1021/jo01206a004

7. Wang, Y.; Liu, Y.; Wiley, D.; Zhao, S.; Tang, Z. J. Mater. Chem. A 2021, 9, 18974-18993. doi:10.1039/d1ta02745j

See for a recent review.

8. Yoshida, J.-i. Flash Chemistry: Fast Organic Synthesis in Microsystems; John Wiley \& Sons: Chichester, UK, 2008.

9. Ehrich, H.; Linke, D.; Morgenschweis, K.; Baerns, M.; Jähnisch, K. Chimia 2002, 56, 647-653. doi:10.2533/000942902777680063

10. Matsubara, H.; Hino, Y.; Tokizane, M.; Ryu, I. Chem. Eng. J. 2011, 167, 567-571. doi:10.1016/j.cej.2010.08.086

11. Fukuyama, T.; Tokizane, M.; Matsui, A.; Ryu, I. React. Chem. Eng. 2016, 1, 613-615. doi:10.1039/c6re00159a

12. Strauss, F. J.; Cantillo, D.; Guerra, J.; Kappe, C. O. React. Chem. Eng. 2016, 1, 472-476. doi:10.1039/c6re00135a

13. Hyodo, M.; Iwano, H.; Kasakado, T.; Fukuyama, T.; Ryu, I. Micromachines 2021, 12, 1307. doi:10.3390/mi12111307

14. Zhang, S. S. J. Power Sources 2006, 162, 1379-1394. doi:10.1016/j.jpowsour.2006.07.074 See for a review on electrolyte additives for lithium ion batteries. 15. Ivanov, S.; Sauerteig, D.; Dimitrova, A.; Krischok, S.; Bund, A. J. Power Sources 2020, 457, 228020. doi:10.1016/j.jpowsour.2020.228020

16. Michan, A. L.; Parimalam, B. S.; Leskes, M.; Kerber, R. N.; Yoon, T.; Grey, C. P.; Lucht, B. L. Chem. Mater. 2016, 28, 8149-8159. doi:10.1021/acs.chemmater.6b02282

17. Liu, Y.-H.; Takeda, S.; Kaneko, I.; Yoshitake, H.; Yanagida, M.; Saito, Y.; Sakai, T. RSC Adv. 2016, 6, 75777-75781. doi:10.1039/c6ra15168j

18. Wang, Y.; Nakamura, S.; Tasaki, K.; Balbuena, P. B. J. Am. Chem. Soc. 2002, 124, 4408-4421. doi:10.1021/ja017073i

19. Burns, J. C.; Petibon, R.; Nelson, K. J.; Sinha, N. N.; Kassam, A.; Way, B. M.; Dahn, J. R. J. Electrochem. Soc. 2013, 160, A1668-A1674. doi:10.1149/2.031310jes

20. Xiong, D.; Burns, J. C.; Smith, A. J.; Sinha, N.; Dahn, J. R. J. Electrochem. Soc. 2011, 158, A1431-A1435. doi:10.1149/2.100112jes

21. Aotake, T.; Tanimoto, H.; Hotta, H.; Kuzuhara, D.; Okujima, T.; Uno, H.; Yamada, H. Chem. Commun. 2013, 49, 3661-3663. doi:10.1039/c3cc40827b

22. Geiseler, O.; Müller, M.; Podlech, J. Tetrahedron 2013, 69, 3683-3689. doi:10.1016/j.tet.2013.03.013

23. Revés, M.; Lledó, A.; Ji, Y.; Blasi, E.; Riera, A.; Verdaguer, X. Org. Lett. 2012, 14, 3534-3537. doi:10.1021/ol301545e

24. Dong, S.; Cahill, K. J.; Kang, M.-I.; Colburn, N. H.; Henrich, C. J.; Wilson, J. A.; Beutler, J. A.; Johnson, R. P.; Porco, J. A., Jr. J. Org. Chem. 2011, 76, 8944-8954. doi:10.1021/jo201658y

25. Taffin, C.; Kreutler, G.; Bourgeois, D.; Clot, E.; Périgaud, C. New J. Chem. 2010, 34, 517-525. doi:10.1039/b9nj00536f

26. Huang, X.; Wu, J.; Wang, X.; Tian, Y.; Zhang, F.; Yang, M.; Xu, B.; Wu, B.; Liu, X.; Li, H. ACS Appl. Energy Mater. 2021, 4, 9368-9375. doi:10.1021/acsaem.1c01570

27. Zhang, Y.; Chen, S.; Chen, Y.; Li, L. Mater. Chem. Front. 2021, 5, 3681-3691. doi:10.1039/d1qm00004g

28. Li, H.; Yang, J.; Xu, Z.; Lu, H.; Zhang, T.; Chen, S.; Wang, J.; NuLi, Y.; Hirano, S.-i. ACS Appl. Energy Mater. 2020, 3, 8552-8561. doi:10.1021/acsaem.0c01173 
29. Chai, J.; Liu, Z.; Zhang, J.; Sun, J.; Tian, Z.; Ji, Y.; Tang, K.; Zhou, X.; Cui, G. ACS Appl. Mater. Interfaces 2017, 9, 17897-17905.

doi:10.1021/acsami.7b02844

30. Zhao, H.; Zhou, X.; Park, S.-J.; Shi, F.; Fu, Y.; Ling, M.; Yuca, N.; Battaglia, V.; Liu, G. J. Power Sources 2014, 263, 288-295. doi:10.1016/j.jpowsour.2014.04.063

31. Allmand, A. J.; Cunliffe, P. W.; Maddison, R. E. W. J. Chem. Soc., Trans. 1925, 127, 822-840. doi:10.1039/ct9252700822

\section{License and Terms}

This is an open access article licensed under the terms of the Beilstein-Institut Open Access License Agreement (https://www.beilstein-journals.org/bjoc/terms), which is identical to the Creative Commons Attribution 4.0 International License

(https://creativecommons.org/licenses/by/4.0). The reuse of material under this license requires that the author(s),

source and license are credited. Third-party material in this article could be subject to other licenses (typically indicated in the credit line), and in this case, users are required to obtain permission from the license holder to reuse the material.

The definitive version of this article is the electronic one which can be found at: https://doi.org/10.3762/bjoc.18.16 